DOI: https://doi.org/10.24867/03CG14Štrbac

\title{
TEHNOLOŠKA ANALIZA OSLANJANJA MEĐUSPRATNE KONSTRUKCIJE STAMBENO-POSLOVNOG OBJEKTA U SMEDEREVU
}

\section{TECHNOLOGICAL ANALYSIS OF A REINFORCED CONCRETE SLAB SUPPORT IN AN APARTMENT - OFFICE BUILDING LOCATED IN SMEDEREVO}

\author{
Mirko Štrbac, Jasmina Dražić, Fakultet tehničkih nauka, Novi Sad
}

\section{Oblast - GRAĐEVINARSTVO}

Kratak sadržaj -U radu je sa tehnološkog aspekta analizirana mogućnost oslanjanja međuspratne AB ploče, skeletne konstrukcije stambeno-poslovnog objekta $u$ tri varijante oslanjanja. Varijanta rešenja su vrednovana na osnovu četiri kriterijuma, a primenom metode višekriterijumske optimizacije izabrano je optimalno rešenje.

Ključne reči: međuspratna ploča, skeletna konstrukcija, oslanjanje, višekriterijumska optimizacija

\begin{abstract}
This paper analyses, from technological view, possibility of reinforced concrete slab support for scelet construction of an apartment - office building, considering three alternative solutions. Evaluation of these alternative solutions is based on four different criteria and the optimal solution has been chosen by use of multi-criteria optimisation.
\end{abstract}

Keywords: slab, scelet construction, support, multicriteria optimisation

\section{UVOD}

Zadatak savremenog graditeljstva jeste izgraditi objekat sa što nižim troškovima u što kraćem roku, a da se pri tome obezbedi visok kvalitet. Da bi se to ostvarilo, neophodno je $u$ analize uvrstiti mnogobrojne i raznovrsne elemente i faktore koji utiču na proces izgradnje, da bi se došlo do optimalnog rešenja.

U ovom radu je sa tehnološkog aspekta analizirana mogućnost oslanjanja međuspratne ploče stambenoposlovnog objekta spratnosti $\mathrm{P}+7$, u Smederevu. Promena načina oslanjanja međuspratne konstrukcije, razmatrana je $\mathrm{u}$ tri varijante: $\mathrm{V} 1$ - ploča direktno oslonjena na stubove, V2 - ploča oslonjena na $\mathrm{AB}$ grede koje se pružaju u oba ortogonalna pravca i V3 - ploča oslonjena na $\mathrm{AB}$ grede koje se pružaju u jednom pravcu.

Varijantna rešenja su vrednovana na osnovu pokazatelja tehnološke analize, utroška osnovnog materijala (beton, čelik), vremena potrebnog za izvođenje konstrukcijskih elemenata na tipskoj etaži i jednog sinteznog kvalitativnog pokazatelja, sa ciljem da se predloži najpovoljniji način oslanjanja međuspratne konstrukcije (optimalno rešenje).

\section{NAPOMENA:}

Ovaj rad proistekao je iz master rada čiji mentor je bila dr Jasmina Dražić, red.prof.

\section{SKELETNE KONSTRUKCIJE I MOGUĆNOSTI OSLANJANJA MEĐUSPRATNE KONSTRUKCIJE}

Skeletne konstrukcije su sistemi kod kojih se opterećenje prenosi putem međuspratnih konstrukcija, AB greda $\mathrm{i}$ stubova na temelje i temeljno tlo.

Zidovi nisu noseći elementi, sem AB zidova za ukrućenje koji primaju horizontalna opterećenja, pre svega seizmičko opterećenje.

Stubovi su vitki vertikalni noseći elementi konstrukcije koji primaju vertikalno opterećenje i kod kojih je jedna dimenzija (visina) izrazito veća od druge dve.

AB grede su horizontalni noseći elementi konstrukcije koji primaju horizontalna i vertikalna opterećenja i horizontalno ih prenose do oslonaca, odnosno vertikalnih nosećih elemenata.

Međuspratna konstrukcija (ploča) je površinski ravan nosač, čije su dve dimenzije (dužina i širina) izrazito veće od treće (visine). Ploča svojom površinom prima opterećenje i prenosi ga na grede ili direktno na stubove.

U zavisnosti od načina na koji se opterećenje sa ploče prenosi na stubove, razlikujemo sledeće tipove oslanjanja međuspratne konstrukcije [1]:

Ploča oslonjena na $\mathrm{AB}$ grede u jednom pravcu opterećenje se prenosi u pravcu upravnom na grede, a grede dalje opterećenje prenose na stubove. U tom pravcu se računa potrebna, „glavna“ armatura, a podeona armatura je određena Poasonovim koeficijentom, čije su vrednosti od 0,16 do 0,20.

$>$ Ploča oslonjena na $\mathrm{AB}$ grede $\mathrm{u}$ dva ortogonalna pravca - opterećenje se prenosi u oba pravca na grede koje se nalaze po ivici ploče te se proračunom dobija armatura u oba pravca.

> Ploča direktno oslonjena na stubove - i kod ovih ploča opterećenje se prenosi u oba pravca, ali direktno na stubove, a armiraju se takođe u oba pravca. Problem kod ovog tipa je probijanje ploče na mestu oslanjanja sa stubom usled prekoračenja „,dopuštenih“ smičućih napona.

$>$ Ploče oslonjene na stubove preko kapitela (pečurkaste ploče) - primarni zadatak kapitelne konstrukcije je da tavaničnu konstrukciju obezbedi od proboja, odnosno da poveća smičuću nosivost ploče. 


\section{TEHNOLOŠKA ANALIZA VARIJANTI OSLA- NJANJA MEĐUSPRATNE KONSTRUKCIJE}

Zgrada koja je predstavljala podlogu za analize u ovom radu nalazi se u Smederevu. Arhitektonskim rešenjem je predviđeno da se u prizemlju nalaze poslovni prostori dok su na spratovima stambene jedinice. Sprat ima po jedan trosoban stan, tri dvosobna i dve garsonjere.

Osnova zgrade je nepravilnog oblika i svaka etaža ima istu površinu od $549 \mathrm{~m}^{2}$. Visina prizemlja je $3,5 \mathrm{~m}$, a svaka od šest etaža ima visinu $2,7 \mathrm{~m}$, pa je ukupna visina objekta $20,47 \mathrm{~m}$. Objekat se završava neprohodnom krovnom terasom.

\subsection{Varijantna rešenja}

Problem oslanjanja međuspratne konstrukcije rešen je analizom tri varijantna rešenja.

\section{PRVO VARIJANTNO REŠENJE (V1)}

Ovo rešenje podrazumeva skeletnu konstrukciju za koju je (slika 1):

> Konstrukcijski sistem bezgredni, a međuspratna konstrukcija $(\mathrm{d}=16 \mathrm{~cm})$, je krstasto armirana i direktno se oslanja na stubove.

$>$ Stubovi su kvadratnog poprečnog preseka.

> Obodni stubovi su dimenzija $45 \times 45 \mathrm{~cm}$, a unutrašnji stubovi su dimenzija $35 \times 35 \mathrm{~cm}$. Izuzetak su stubovi na preseku ose D i osa 4 i 5, kao i na preseku ose E i ose 5 , koji su dimenzija $50 \times 50 \mathrm{~cm} \mathrm{i} \mathrm{40x40cm,} \mathrm{redom.}$

> Postoje 3 zida za ukrućenje u x-pravcu i 4 u y-pravcu. Debljina svih zidova je $25 \mathrm{~cm}$.

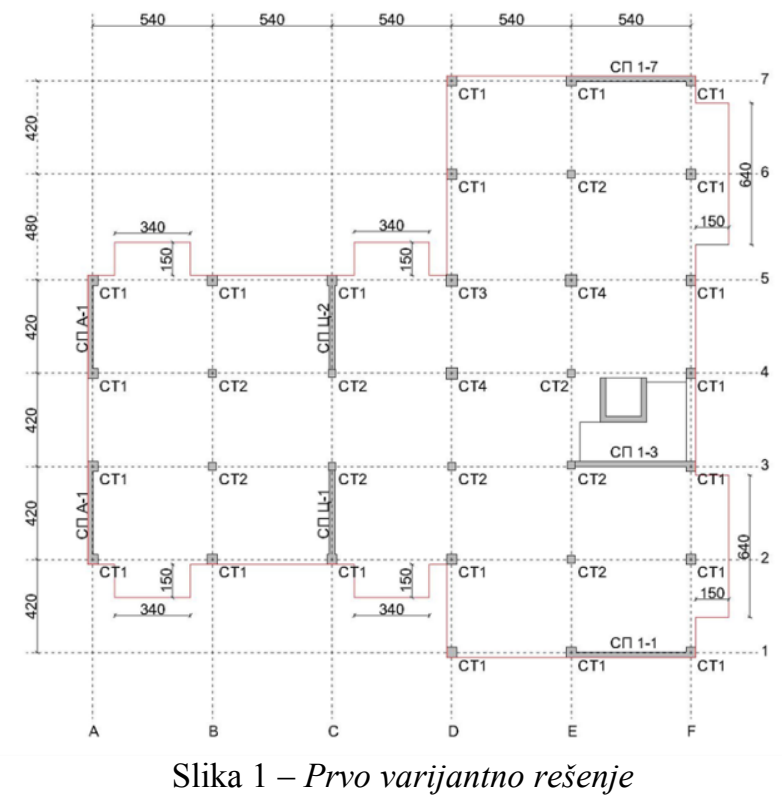

DRUGO VARIJANTNO REŠENJE (V2)

Drugo rešenje podrazumeva skeletnu konstrukciju za koju je (slika 2):

$>$ Konstrukcijski sistem gredni, a međuspratna konstrukcija je krstasto armirana i oslanja se na grede u oba pravca.

$>$ Debljina ploče je $12 \mathrm{~cm}$.

$>$ Grede su pravougaonog oblika, dimenzija, $25 \times 45 \mathrm{~cm}$.

> Stubovi su kvadratnog poprečnog preseka, dimenzija $40 \mathrm{x} 40 \mathrm{~cm}$.
Postoje 3 zida za ukrućenje u x-pravcu i 4 u y-pravcu. Debljina svih zidova je $25 \mathrm{~cm}$.

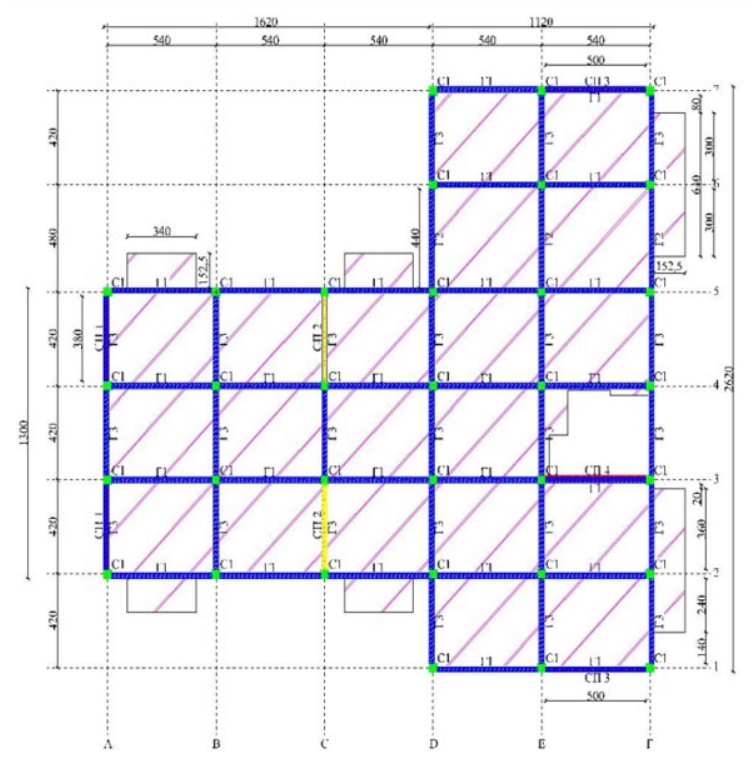

Slika 2 - Drugo varijantno rešenje

\section{TREĆE VARIJANTNO REŠENJE (V3)}

Ovo rešenje podrazumeva skeletnu konstrukciju za koju je (slika 3):

> Konstrukcijski sistem sa monolitnom pločom i gredama u jednom pravcu.

$>$ Debljina ploče je $14 \mathrm{~cm}$.

$>$ Grede su pravougaonog poprečnog preseka, dimenzija, $25 \times 50 \mathrm{~cm}$.

$>$ Stubovi su pravougaonog poprečnog preseka, dimenzija $45 \times 25 \mathrm{~cm}$.

$>$ Postoje 3 zida za ukrućenje u x-pravcu i 4 u y-pravcu. Debljina svih zidova je $25 \mathrm{~cm}$.

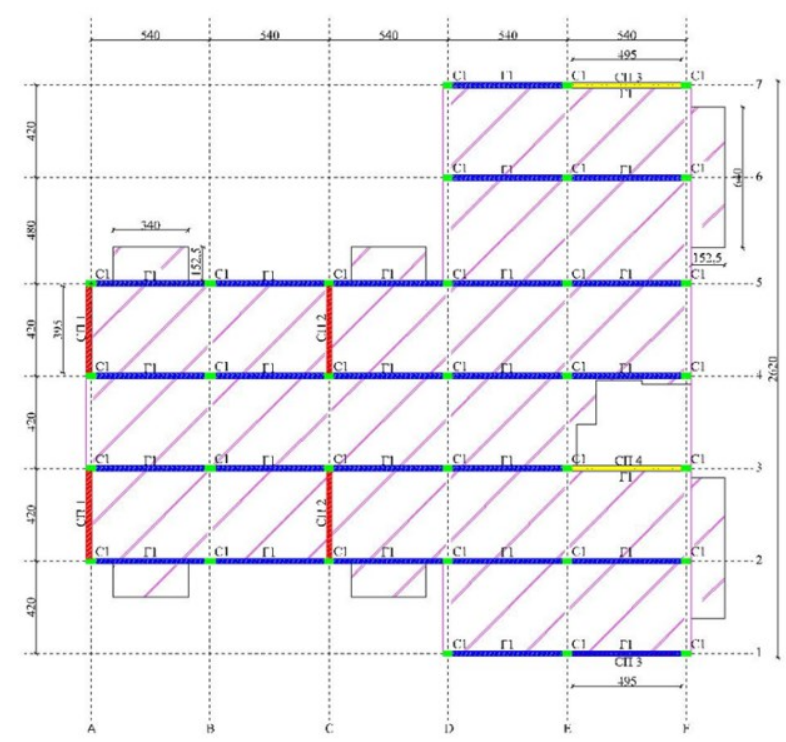

Slika 3 - Treće varijantno rešenje

\subsection{Kriterijumi vrednovanja i rezultati analize}

Varijantna rešenja su vrednovana na osnovu pokazatelja tehnološke analize, utroška osnovnog materijala (beton, čelik) i vremena potrebnog za izvođenje primarnih konstrukcijskih elemenata na tipskoj etaži. 
U analizu je uvršten i jedan sintezni pokazatelj kvalitativnog karaktera koji je obuhvatio tri aspekta (arhitektonski, konstrukcijski i izvođački).

\subsubsection{Kriterijum K1 - količina betona}

Za svako varijantno rešenje oslanjanja međuspratne konstrukcije, na osnovu specifikacije elemenata primarne konstrukcije na posmatranoj (tipskoj) etaži, sračunata je potrebna količina betona za ugradnju. U tabeli 1 su prikazane količine betona po elementima i ukupna količina za svako od varijantnih rešenja.

Tabela 1 - Količina betona za svaku od varijanti

\begin{tabular}{|c|c|c|c|}
\hline \multirow{2}{*}{ Element } & \multicolumn{3}{|c|}{ Količina betona $\left[\mathrm{m}^{3}\right]$} \\
\cline { 2 - 4 } & $\mathbf{V 1}$ & $\mathbf{V 2}$ & V3 \\
\hline Stubovi & 14,06 & 13,62 & 9,51 \\
\hline Zidovi & 19,04 & 17,52 & 16,86 \\
\hline Ploča & 84,85 & 55,61 & 68,27 \\
\hline Grede & - & 23,44 & 16,09 \\
\hline Ukupno & $\mathbf{1 1 7 , 9 5}$ & $\mathbf{1 1 0 , 1 9}$ & $\mathbf{1 1 0 , 7 3}$ \\
\hline
\end{tabular}

Za svako varijantno rešenje, ukupna količina betona za sve elemente konstrukcije je podeljena sa površinom tipske etaže i dobijena je numerička vrednost prvog kriterijuma. U tabeli 2 prikazane su te vrednosti.

Tabela 2 - Numerička vrednost kriterijuma K1

\begin{tabular}{|c|c|c|c|}
\hline & V1 & V2 & V3 \\
\hline $\mathrm{K} 1\left[\mathrm{~m}^{3} / \mathrm{m}^{2}\right]$ & $\mathbf{0 , 2 1 6}$ & $\mathbf{0 , 2 0 2}$ & $\mathbf{0 , 2 0 6}$ \\
\hline
\end{tabular}

\subsubsection{Kriterijum K2 - količina armature}

Količina armature je za prvu konstrukcijsku varijantu izračunata na osnovu podataka iz projektno - tehničke dokumentacije [2], a za drugu i treću varijantu na osnovu iskustvenih normativa, $\mathrm{u}$ zavisnosti od zapremine elemenata (tabela 3).

Tabela 3 - Količina armature za svaku od varijanti

\begin{tabular}{|c|c|c|c|}
\hline \multirow{2}{*}{ Element } & \multicolumn{3}{|c|}{ Količina armature $[\mathrm{kg}]$} \\
\cline { 2 - 4 } & $\mathbf{V 1}$ & $\mathbf{V 2}$ & $\mathbf{V 3}$ \\
\hline Stubovi & 3093,20 & 2996,40 & 2092,20 \\
\hline Zidovi & 2722,72 & 2505,36 & 2410,98 \\
\hline Ploča & 9842,60 & 5282,95 & 7168,35 \\
\hline Grede & - & 2578,40 & 1930,80 \\
\hline Ukupno & $\mathbf{1 5 6 5 8 , 5 2}$ & $\mathbf{1 3 3 6 3 , 1 1}$ & $\mathbf{1 3 6 0 2 , 3 3}$ \\
\hline
\end{tabular}

Drugi kriterijum predstavlja prosečnu količinu armature po jedinici površine posmatrane etaže. U tabeli 4 su prikazane numeričke vrednosti ovog kriterijuma za svako varijantno rešenje.

Tabela 4 - Numerička vrednost kriterijuma K2

\begin{tabular}{|c|c|c|c|}
\hline & V1 & V2 & V3 \\
\hline K2 $\left[\mathrm{kg} / \mathrm{m}^{2}\right]$ & 28,662 & 24,460 & 25,331 \\
\hline
\end{tabular}

\subsubsection{Kriterijum K3 - vreme izvođenja}

Vreme izvođenja radova (konstrukcijski elementi) na posmatranoj etaži, kao i formiranje radnih brigada, analizirano je kroz normative i standarde rada u građevinarstvu [3].
Usvojeno je osmočasovno radno vreme, sa efektivnim radim vremenom od sedam časova. Aktivnosti vezane za izvođenje konstrukcijskih elemenata obuhvataju:

$>$ Armiranje stubova i zidova,

$>$ Montažu oplate stubova i zidova,

$>$ Betoniranje stubova i zidova,

$>$ Očvršćavanje betona stubova i zidova,

$>$ Demontažu oplate stubova i zidova,

$>$ Montažu oplate međuspratne ploče

$>$ Armiranje međuspratne ploče

$>$ Betoniranje međuspratne ploče

$>$ Očvršćavanje betona međuspratne

$>$ Demontažu oplate međuspratne ploče

Za svaku aktivnost i sve tri varijante detaljno je proračunato, potrebno vreme i radna brigada za njeno izvođenje [3]. Kako bi vrednovanje bilo što realnije, za iste aktivnosti u svim varijantama usvajana je ista radna brigada. Trajanje svih aktivnosti izražno u satima i danima.

Radovi na izvođenju konstrukcijskih elemenata tipske etaže se odvijaju po tehnološkim zahtevima. $\mathrm{Na}$ osnovu urađenih mrežnih planova (modela procesa izgradnje), mogu se uočiti aktivnosti na kritičnom putu. To su aktivnosti koje određuju ukupno vreme izvođenja radova na elementima konstukcije.

Treći kriterijum za vrednovanje varijanti podrazumeva prosečnu vrednost ukupnog vremena za izvođenje svih konstrukcijskih elemenata na tipskoj etaži. Kada podelimo ukupno vreme izvođenja svake varijante sa odgovarajućom površinom etaže, dobijamo numeričku vrednost trećeg kriterijuma, koja je prikazana u tabeli 5 .

Tabela 5 - Numerička vrednost kriterijuma K3

\begin{tabular}{|c|c|c|c|}
\hline & V1 & V2 & V3 \\
\hline $\mathrm{K} 3\left[\mathrm{~h} / \mathrm{m}^{2}\right]$ & $\mathbf{0 , 4 6 7}$ & $\mathbf{0 , 4 5 8}$ & $\mathbf{0 , 4 8 8}$ \\
\hline
\end{tabular}

\subsubsection{Kriterijum K4 - sintezni kriterijum kvalitativnog karaktera}

Ovo je kriterijum koji će oceniti varijantna rešenja sa nekoliko aspekata (arhitektonskog, konstrukcijskog i izvođačkog).

Prvo varijantno rešenje, gde je puna ploča bez grednih nosača, je u arhitektonskom pogledu najprihvatljivije, jer konstrukcijsko rešenje obezbeđuje prazan prostor koji nema nikakvih ograničenja u pogledu rasporeda pregradnih zidova.

U konstrukcijskom smislu, najbolje je drugo rešenje, jer je linijsko oslanjanje ploče po ivici, u naponsko deformacijskom pogledu, znatno povoljnije nego lokalno oslanjanje.

Jednostavnost izrade oplate, manja količina armaturnih šipki kod ploče direktno oslonjene na stubove, čine tu varijantu najpovoljnijom za izvođenje.

Varijantama su date ocene od 1 do 3 za svaki aspekt pojedinačno, tako da ocena 1 predstavlja najpovoljnije rešenje po tom aspektu. Sintezni kvalitativni kriterijum predstavlja srednju vrednost ukupnog zbira ocena za varijantna rešenja sa sva tri aspekta. Vrednosti ovog kriterijuma prikazane su u tabeli 6 . 
Tabela 6 - Numerička vrednost kriterijuma $K 4$

\begin{tabular}{|c|c|c|c|}
\hline & V1 & V2 & V3 \\
\hline K4 & 1,667 & 2,333 & 2,000 \\
\hline
\end{tabular}

\section{VIŠEKRITERIJUMSKA OPTIMIZACIJA I PREDLOG NAJPOVOLJNIJEG REŠENJA}

Problem optimizacije svodi se na određivanje ekstrema vektorske kriterijumske funkcije. Za tri varijantna rešenja:

V1 - ploča direktno oslonjena na stubove

V2 - ploča oslonjena na AB grede koje se pružaju u oba ortogonalna pravca

V3 - ploča oslonjena na AB grede koje se pružaju u jednom pravcu.

predložen je model optimizacije u obliku:

$$
\mathrm{F}(\mathrm{x})=\min \left(\mathrm{f}_{1}, \mathrm{f}_{2}, \mathrm{f}_{3}, \mathrm{f}_{4}\right)
$$

gde su:

$\mathrm{f}_{1}$ - količina ugrađenog betona $\left[\mathrm{m}^{3} / \mathrm{m}^{2}\right]$

$\mathrm{f}_{2}$ - količina ugrađene armature $\left[\mathrm{kg} / \mathrm{m}^{2}\right]$

$\mathrm{f}_{3}$ - vreme izvođenja [časova $/ \mathrm{m}^{2}$ ]

$\mathrm{f}_{4}$ - kvalitativni sintezni pokazatelj

Za rešavanje zadatka usvojena je metoda višekriterijumske optimizacije, metoda kompromisnog programiranja i metoda kompromisnog rangiranja [4]. Rezultati optimizacije (redosled varijantnih rešenja) prikazani su u tabelama 7, 8, 9 i 10.

Tabela 7 - Metoda kompromisnog programiranja-rě̌enje je najbolje po svim krtierijumima posmatranim zajedno

\begin{tabular}{|c|c|c|c|}
\hline & $\mathbf{V 1}$ & $\mathbf{V 2}$ & $\mathbf{V 3}$ \\
\hline redosled & 3 & $\mathbf{1}$ & 2 \\
\hline
\end{tabular}

Tabela 8 - Metoda kompromisnog programiranja-rě̌enje je geometrijski najbliže idealnoj tački

\begin{tabular}{|c|c|c|c|}
\hline & $\mathbf{V 1}$ & $\mathbf{V 2}$ & $\mathbf{V 3}$ \\
\hline redosled & 3 & $\mathbf{1}$ & 2 \\
\hline
\end{tabular}

Tabela 9 - Metoda kompromisnog programiranjaprioritet je dat kriterijumu sa najvećim odstupanjem

\begin{tabular}{|c|c|c|c|}
\hline & $\mathbf{V 1}$ & $\mathbf{V 2}$ & $\mathbf{V 3}$ \\
\hline redosled & 3 & $\mathbf{1}$ & 2 \\
\hline
\end{tabular}

Tabela 10 -Metoda kompromisnog rangiranja

\begin{tabular}{|c|c|c|c|}
\hline & V1 & V2 & V3 \\
\hline Qj $\left(v_{1}=0,0\right)$ & 3 & $\mathbf{1}$ & 2 \\
\hline Qj $\left(v_{1}=0,3\right)$ & 3 & $\mathbf{1}$ & 2 \\
\hline Qj $\left(v_{1}=0,6\right)$ & 3 & $\mathbf{1}$ & 2 \\
\hline Qj $\left(v_{1}=0,9\right)$ & 3 & $\mathbf{1}$ & 2 \\
\hline Qj $\left(v_{1}=1,0\right)$ & 3 & $\mathbf{1}$ & 2 \\
\hline
\end{tabular}

$\mathrm{Na}$ osnovu tehnološke analize, prema metodi višekriterijumske optimizacije metodi kompromisnog programiranja i kompromisnog rangiranja, najpovoljnije varijantno rešenje je DRUGO VARIJANTNO REŠENJE, u kome je ploča oslonjena na grede $u$ dva ortogonalna pravca.

\section{ZAKLJUČAK}

U ovom radu je urađena tehnološka analiza oslanjanja međuspratne konstrukcije, za stambeno - poslovni objekat u Smederevu, sa ciljem da se predloži najpovoljnije (optimalno) rešenje.

Konstrukcijska rešenja su razmatrana u tri varijante:

> prvo varijantno rešenje - ploča direktno oslonjena na stubove,

$>$ drugo varijantno rešenje - ploča oslonjena na grede $u$ dva pravca,

$>$ treće varijantno rešenje - ploča oslonjena na grede $u$ jednom pravcu.

Varijantna rešenja oslanjanja međuspratne konstrukcije su vrednovana na osnovu četiri kriterijuma:

$>\mathrm{K} 1$ - količine betona potrebne za izradu primarne konstrukcije,

$>\mathrm{K} 2$ - količine armature (čelika), potrebne za izradu primarne konstrukcije,

$>\mathrm{K} 3$ - potrebnog vremena za izvođenje primarne konstrukcije i

$>\mathrm{K} 4-$ sinteznog kvalitativnog kriterijuma.

Numerički podaci kvantitativnih pokazatelja (K1, K2 i K3) izračunati su za sva tri varijantna rešenja, za pripadajuće konstrukcijske elemente na tipskoj etaži. Kriterijum K4 predstavlja srednju vrednost zbira ocena varijantnih rešenja sa tri aspekta: arhitektonskog, konstrukcijskog i izvođačkog.

Primenom metode višekriterijumske optimizacije, metode kompromisnog programiranja i kompromisnog rangiranja, dobijena je rang lista povoljnosti rešenja. Kako obe metode, za sve strategije odlučivanja imaju konzistentne izlazne rezultate, drugo varijantno rešenje, u kome je međuspratna konstrukcija oslonjena na grede u oba pravca, može se predložiti kao najpovoljnije (optimalno) rešenje za stambeno - poslovni objekat u Smederevu.

\section{LITERATURA}

[1] “Beton i armirani beton prema BAB87”, Građevinski fakultet, Univerzitet u Beogradu, Beograd, 1995.

[2] "Štrbac, M.: "Projekat konstrukcije višespratne armiranobetonske zgrade u Smederevu”, diplomski rad, Fakultet tehničkih nauka, Novi Sad, 2015.

[3] Normativi i standardi rada u građevinarstvu”, dvanaesto izmenjeno i dopunjeno izdanje, Građevinska knjiga DOO, Beograd, 2008.

[4] Opricović,S.: „Optimizacija sistema“, Građevinski fakultet, Univerzitet u Beogradu, Beograd, 1992.

\section{Kratka biografija:}

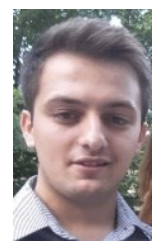

Mirko Štrbac rođen je u Sanskom Mostu 1991. god. Master rad na Fakultetu tehničkih nauka iz oblasti Građevinarstva - Organizacija i tehnologija građenja, odbranio je 2018.god.

Kontakt: strbacmirko@yahoo.com

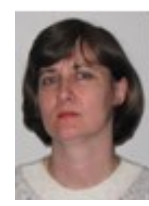

Jasmina Dražić, rođena je u Novom Miloševu 1958. godine. Doktorirala je na Fakultetu tehničkih nauka 2005.god. a od 2015. godine je u zvanju redovnog profesora. Oblast Zgradarstvo - građevinske konstrukcije i tehnologije. 